\title{
An increase in exhaled nitric oxide is not associated with activity in pulmonary sarcoidosis
}

\author{
D. Ziora*, K. Kałuska\#, J. Kozielski*
}

An increase in exhaled nitric oxide is not associated with activity in pulmonary sarcoidosis. D. Ziora, K. Kaluska, J. Kozielski. (C) ERS Journals Ltd 2004.

ABSTRACT: Exhaled nitric oxide (eNO) concentration measurement may permit the noninvasive estimation of the severity of airways inflammation in respiratory tract diseases. The aim of this study was to evaluate the correlation between eNO concentration and the activity of sarcoidosis, its radiographic staging and lung function abnormalities.

eNO concentration was measured using a chemiluminescent analyser in 27 patients with sarcoidosis and 11 control subjects.

The mean eNO concentration in patients with sarcoidosis was significantly higher $(6.7 \pm 0.50$ parts per billion (ppb)) than that in the control group $(5.17 \pm 0.73 \mathrm{ppb})$. eNO concentration was similar in radiographic stage I, II and III patients $(6.53,7.32$ and $6.24 \mathrm{ppb}$, respectively). No significant difference was found in eNO concentration between the patients with active and inactive disease. Nor did eNO concentration differ between the patients with and without indication for therapy. There was no significant correlation between eNO concentration and forced vital capacity or bronchoalveolar lavage fluid lymphocyte and macrophage counts. There was a weak correlation between eNO concentration and single-breath carbon monoxide diffusing capacity of the lung.

Exhaled nitric oxide concentration is elevated in patients with sarcoidosis. This concentration does not depend on the radiographic staging, activity or progression of the disease.

Eur Respir J 2004; 24: 609-614.
*Dept of Pneumonology, Silesian University of Medicine, Zabrze, and ${ }^{\#}$ Clinic of Lung Diseases, Tychy, Poland.

\section{Correspondence: D. Ziora}

Dept of Pneumonology

Silesian University of Medicine

Koziołka 1

41803 Zabrze

Poland

Fax: 48322715608

E-mail: ftpulmza@infomed.slam.katowice.pl

Keywords: Exhaled nitric oxide nitric oxide

sarcoidosis

Received: October 52003

Accepted after revision: May 92004
Nitric oxide is the most extensively studied exhaled marker. Abnormalities in exhaled NO (eNO) concentration have been documented in several lung diseases, particularly asthma [1] and bronchiectasis [2].

NO plays a key role in airways as a neurotransmitter, vasodilator and inflammatory mediator. It is synthesised from the amino acid L-arginine by an enzyme, NO synthase (NOS), in the presence of a variety of cofactors [3]. There exist at least three distinct isoforms. Two of these enzymes are constitutively expressed and activated by small increases in intracellular calcium concentration, secondary to cell activation. Neuronal NOS (NOS1) is predominantly expressed in neurons, and endothelial NOS (NOS3) in endothelial cells. The third enzyme is inducible (iNOS; NOS2), which exhibits much greater activity and is independent of calcium concentration [4]. Originally described in macrophages, iNOS has subsequently been found in many cell types. This isoform of the enzyme, unlike the constitutive isoforms, is inhibited by corticosteroids [5].

Corticosteroids may reduce NO concentration by directly inhibiting the induction of iNOS or suppressing the proinflammatory cytokines that induce iNOS [6]. Other authors maintain that corticosteroids exert an indirect effect by suppression of inflammatory cytokines or a reduction in inflammatory cell infiltrate in the airways [7]. iNOS may be induced by endotoxin, viral infections and inflammatory cytokines in a variety of cells: fibroblasts, lymphocytes, neutrophils, macrophages, and epithelial cells [3, 8, 9]. Alveolar macrophages are the potential source of iNOS in interstitial lung diseases [10, 11].
Sarcoidosis is a multisystem disorder of unknown cause. The early sarcoid reaction is characterised by the accumulation of increased numbers of activated T-cells and macrophages at sites of ongoing inflammation, notably in the lung. Sarcoid T-lymphocytes bear the helper CD4 phenotype and spontaneously release interleukin-2 and interferon gamma (IFN- $\gamma$ ), which is able to induce the NOS pathway [12]. Sarcoid alveolar macrophages release a great variety of cytokines, including tumour necrosis factor- $\alpha(\mathrm{TNF}-\alpha)$, which may upregulate activation of iNOS [11].

It was investigated whether eNO concentration might be elevated in patients with sarcoidosis and whether any such elevation might be related to the extent of sarcoidosis. It should be noted that two previous studies concerning pulmonary sarcoidosis have shown the opposite results. These studies were performed in a small group of patients with sarcoidosis $[13,14]$.

\section{Material and methods}

Twenty-seven nonsmoking patients with sarcoidosis (18 males and nine females, aged 26-67 yrs) were studied. All were Caucasian. In all cases, the diagnosis of sarcoidosis was confirmed by transbronchial or lymph node biopsy. The duration of disease was $\leqslant 2$ yrs. All chest radiographs were abnormal: six patients exhibited radiographic stage I (bilateral hilar lymphadenopathy), 10 stage II (bilateral hilar adenopathy accompanied by parenchymal infiltration) and 11 
stage III (parenchymal infiltration without hilar adenopathy) disease.

Based on American Thoracic Society, European Respiratory Society (ERS) and World Association of Sarcoidosis and Other Granulomatous Disorders criteria (clinical picture, radiological features, biochemical tests and bronchoalveolar lavage (BAL)), 21 patients showed active sarcoidosis, whereas six had inactive disease [11].

All patients underwent spirometry and 20 measurements of single-breath carbon monoxide diffusing capacity of the lung (DL,CO). These tests were performed using a Transfer-Screen II apparatus (Jaeger, Würzburg, Germany). The results were expressed as a percentage of the predicted value [15]. Decreased exercise capacity and decreased arterial oxygen tension, along with abnormal lung function test results (spirometry and $D \mathrm{~L}, \mathrm{CO}$ ), the progression of changes on radiographic imaging (chest radiographs and computed tomography scans) and clinical symptoms, were used to determine indication for treatment. On the basis of these criteria, it was decided that treatment should be introduced in 12 patients. None of the patients had received corticosteroids before eNO measurement.

BAL was carried out in 20 patients according to ERS guidelines [16], as described previously [17]. The total cell count and differential cell counts were calculated for the BAL fluid. The numbers of lymphocytes and macrophages per millilitre of BAL fluid were determined. The methodology used has been reported elsewhere [17, 18].

The control group consisted of 11 healthy nonsmoking volunteers (eight males and three females, aged 31-52 yrs) with no history of atopy and no symptoms of respiratory tract infection. Spirometric results were normal in all volunteers.

The Medical University of Silesia Bioethical Committee approved the study protocols.

\section{Exhaled nitric oxide measurement}

eNO concentration was measured by means of a Sievers 280 NO analyser (Sievers Instruments, Inc., Boulder, CO, USA). The measurements were performed according to ERS recommendations [19]. The NO analyser is a high-sensitivity detector for measuring NO based on a gas-phase chemiluminescent reaction between $\mathrm{NO}$ and ozone. The sensitivity of the analyser for measurement of gas-phase $\mathrm{NO}$ is $<1$ part per billion (ppb) by volume. The instrument was calibrated daily as recommended. Before each test, automatic NO zeroing was performed. The ambient NO concentration for each manoeuvre was also recorded. All subjects stood and did not use noseclips. They exhaled slowly from total lung capacity to residual volume through mouthpiece tubing connected to the NO analyser against a resistance of $10 \mathrm{cmH}_{2} \mathrm{O}$. This manoeuvre allowed exclusion of nasopharyngeal NO from the exhaled air (soft palate closed). The measured parameters (NO concentration, flow and pressure) were observed on a monitor as a function of time. Participants repeated the manoeuvre until six acceptable tests were performed. Peak NO concentration was measured. The mean of six endexpiratory NO concentrations was calculated for each subject.

\section{Statistical analysis}

Data are reported as mean \pm SEM. Medians are also reported. The comparison between groups was performed using the Mann-Whitney U-test. Multiple comparisons were carried out using the Kruskal-Wallis test.

Correlation between eNO concentration and other variables

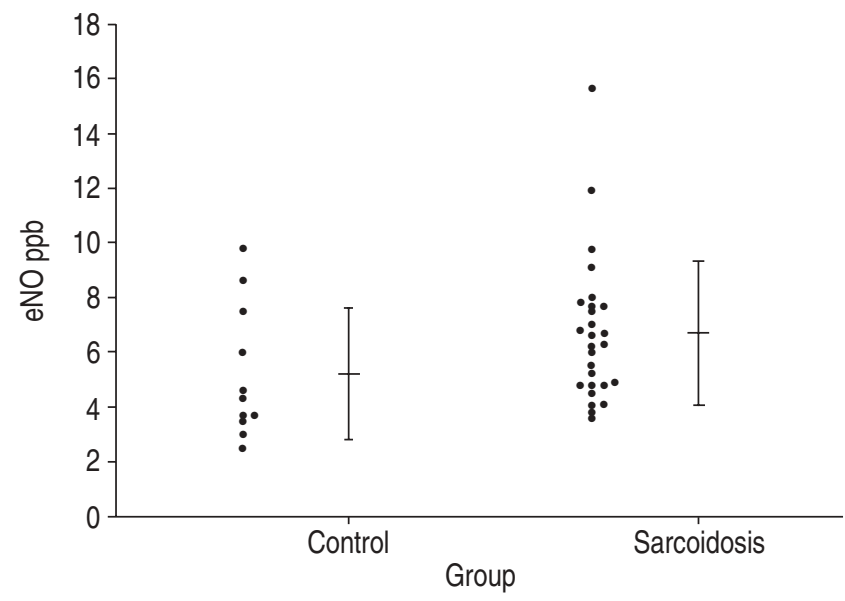

Fig. 1.-Exhaled nitric oxide (eNO) concentration in patients with sarcoidosis and controls. Vertical bars represent mean \pm SEM. ppb: parts per billion. $\mathrm{p}=0.050$.

was sought for using the Pearson test for quantitative and the Spearman test for qualitative data.

A p-value of $\leqslant 0.05$ was considered significant.

\section{Results}

The mean eNO concentration in patients with sarcoidosis was significantly higher $(6.7 \pm 0.50 \mathrm{ppb}$, median $6.30 ; \mathrm{p}=0.05)$ than that in the control group $(5.17 \pm 0.73 \mathrm{ppb}$, median 4.32$)$ (fig. 1). eNO concentration was similar in patients with different radiographic stages of the disease $(6.53,7.32$ and $6.24 \mathrm{ppb}$ for stages I, II and III, respectively; $\mathrm{p}=0.985$ ) (fig. 2). No significant difference was found in eNO concentration between the patients with active and inactive sarcoidosis $(\mathrm{p}=0.431)$ (fig. 3). Nor was any difference found in eNO concentration between the patients with and without indications for therapy $(\mathrm{p}=0.124)$ (fig. 4). There was no significant correlation between eNO concentration and forced vital capacity $(\mathrm{FVC})(\mathrm{r}=0.163, \mathrm{p}=0.417)$ (fig. 5), nor between eNO concentration and BAL lymphocyte $(r=0.180, p=0.449)$ (fig. 6) or macrophage $(r=-0.007, p=0.974)$ count (fig. 7). Weak

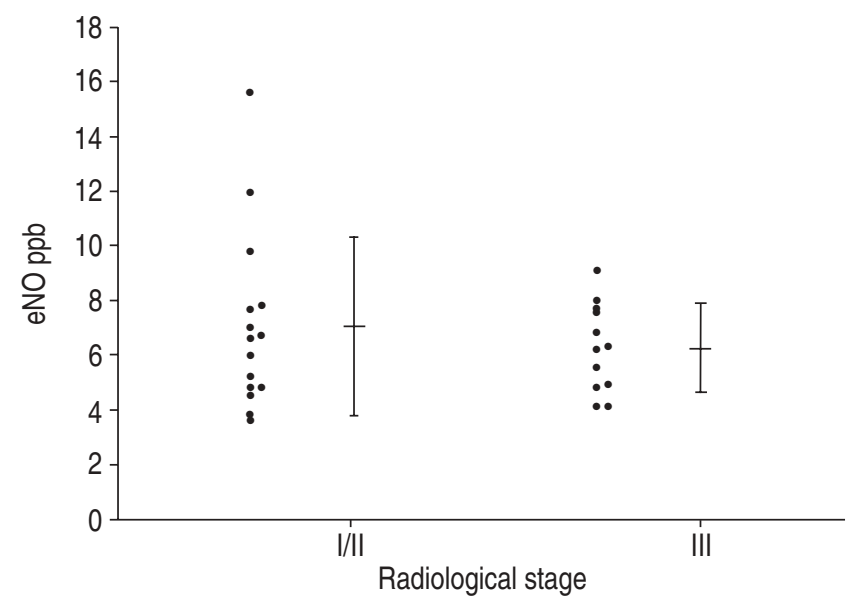

Fig. 2.-Exhaled nitric oxide (eNO) concentration in patients with sarcoidosis of differing radiological stage. Vertical bars represent mean \pm SEM. ppb: parts per billion. $\mathrm{p}=0.985$. 


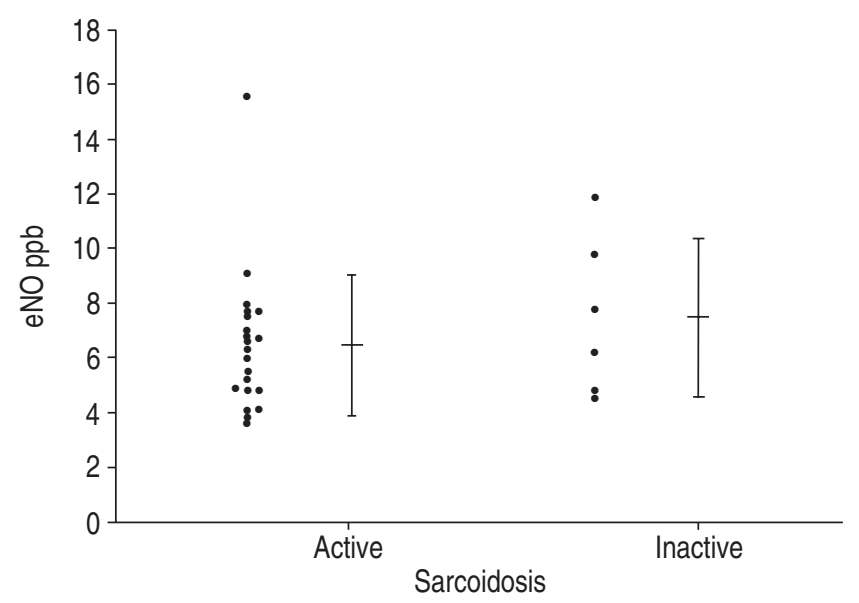

Fig. 3.-Exhaled nitric oxide (eNO) concentration in active and inactive sarcoidosis. Vertical bars represent mean \pm SEM. ppb: parts per billion. $\mathrm{p}=0.431$.

correlation was found between eNO concentration and singlebreath $D \mathrm{~L}, \mathrm{CO}$ (r=0.515, $\mathrm{p}=0.029)$ (fig. 8).

\section{Discussion}

The most important finding of the present study is that elevated eNO concentrations in patients with sarcoidosis do not depend on the activity of the disease. No significant difference was found in eNO concentration between patients with active and inactive sarcoidosis. In sarcoidosis, macrophages and sarcoid granulomas are considered to be a potential source of eNO [13]. MoODLEY et al. [13] supported this hypothesis by immunohistochemical staining of transbronchial biopsy specimen for iNOS activity in patients with sarcoidosis. They demonstrated increased immunohistochemical staining for iNOS in macrophages, T-lymphocytes and fibroblasts, predominantly in granulomas. The higher level of eNO in patients with sarcoidosis might be caused by increasing levels of TNF- $\alpha$ and IFN- $\gamma$, which upregulate iNOS in macrophages. In addition, the increase in eNO concentration observed in patients with active pulmonary

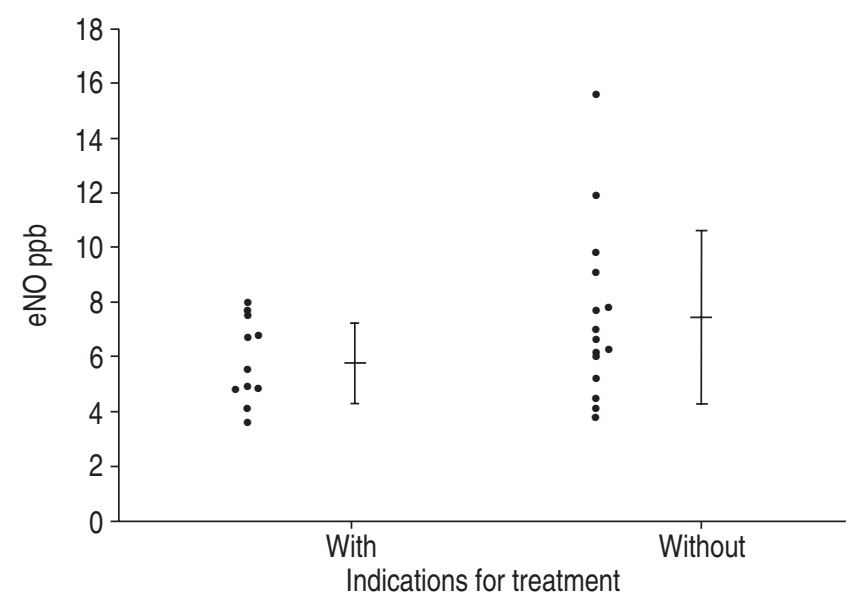

Fig. 4. - Exhaled nitric oxide (eNO) concentration in sarcoid patients with and without indications for treatment. Vertical bars represent mean \pm SEM. ppb: parts per billion. $p=0.124$.

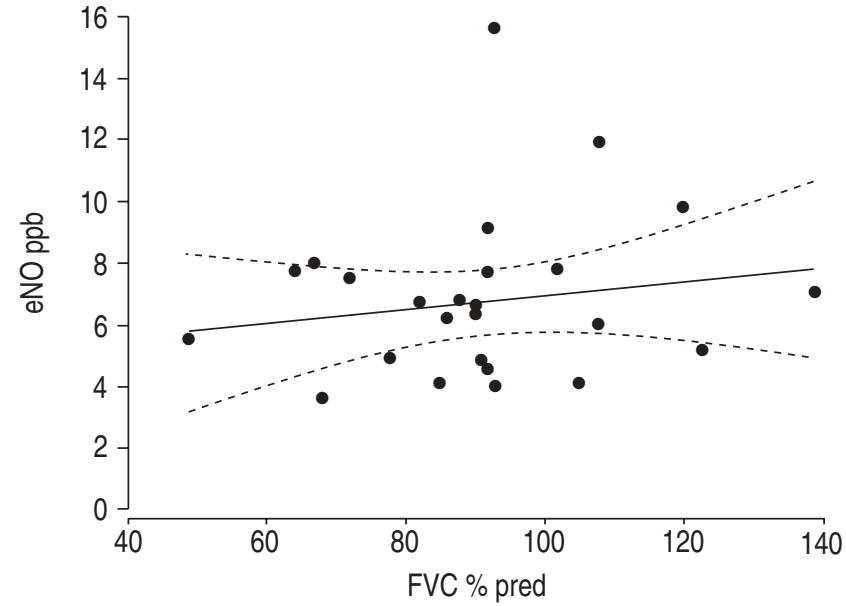

Fig. 5. - Relationship between exhaled nitric oxide (eNO) concentration and forced vital capacity (FVC) in patients with sarcoidosis ( $\_$: regression line; - - - - : 95\% confidence interval). ppb: parts per billion; \% pred: percentage of the predicted value. $r=0.163, p=0.417$.

tuberculosis is due to upregulation of iNOS expression in alveolar macrophages. The mechanism responsible for the upregulation of iNOS and enhanced NO production by human macrophages is probably direct induction by either released cytokines or mycobacterial lipoarabinomannan [20, 21]. By analogy, it may be speculated that the higher observed level of eNO, in patients with sarcoidosis in the present study, might have been caused by raised levels of TNF- $\alpha$ and IFN- $\gamma$, which upregulated iNOS in macrophages. Only alveolar macrophage and alveolar epithelium cell type II coculture in the presence of IFN- $\gamma$ led to expression of iNOS and the corresponding messenger ribonucleic acid. This mechanism probably controls iNOS expression and NO generation in the alveolar compartment and provides protection from nitrous oxide and peroxynitrite radicals in the lung [10]. Another cellto-cell interaction, between alveolar macrophage and lymphocytes, is also important. It is responsible for the early sarcoid reaction in the initial alveolitis described in sarcoidosis [11]. Consequent to this reaction, active mediators are released by activated T-cell, for example IFN- $\gamma$, which is a potent activator of macrophages [12]. A proportion of this cell-specific alveolar macrophage subset in pulmonary

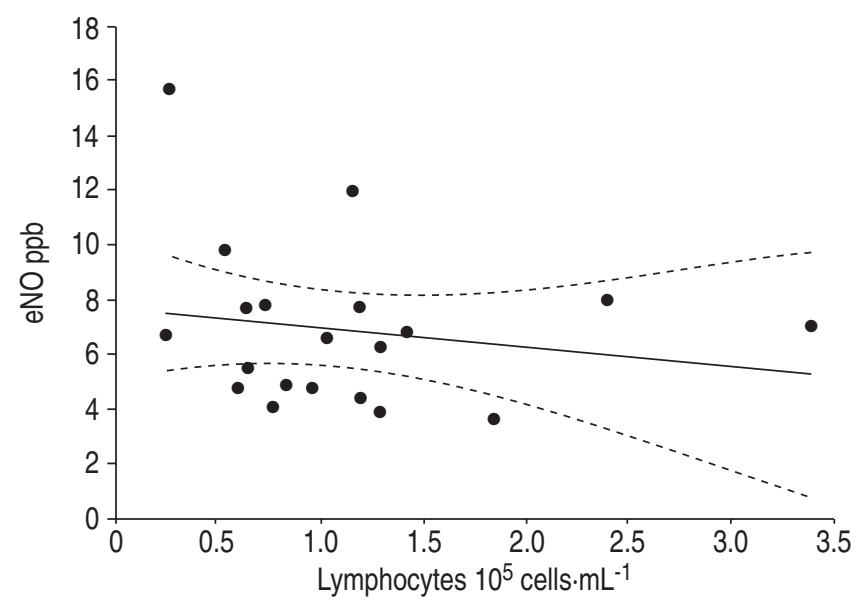

Fig. 6. - Relationship between exhaled nitric oxide (eNO) concentration and bronchoalveolar lavage fluid lymphocyte density in patients with sarcoidosis ( - : regression line; - - - -: $95 \%$ confidence interval). ppb: parts per billion. $\mathrm{r}=-0.180, \mathrm{p}=0.449$. 


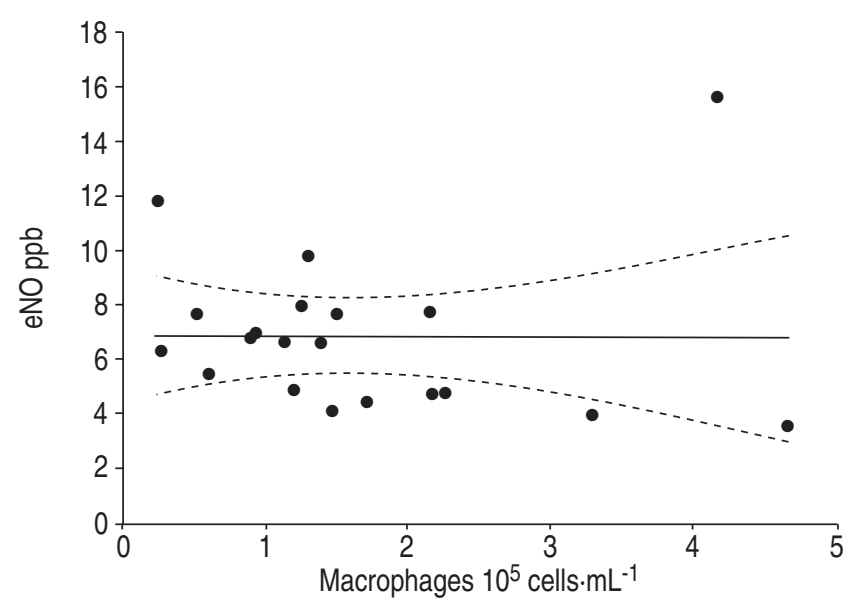

Fig. 7. - Relationship between exhaled nitric oxide (eNO) concentration and bronchoalveolar lavage fluid macrophage density in patients with sarcoidosis ( - : regression line; - - - -: 95\% confidence interval). ppb: parts per billion. $\mathrm{r}=-0.0079, \mathrm{p}=0.974$.

sarcoidosis is capable of suppressing $\mathrm{T}$-cell responses and plays a critical role in determining the fate of granulomas (their resolution or progression to fibrosis) in the lung of patients with sarcoidosis [22]. This seems to be an important factor in the generation of NO. Maturity of macrophages may affect iNOS activity in sarcoidosis. Some macrophages do not differentiate fully in sarcoidosis [22]. The local factors responsible for driving the differentiation of monocytes into macrophages are unknown. A role of NO could not be excluded. Immature macrophages might produce less NO in sarcoidosis [12].

However, there was no significant correlation between eNO concentration and BAL fluid lymphocyte or macrophage density in the present study group. This is in contrast to what would be expected from the alleged role of these cells in iNOS upregulation, resulting from cytokine release, particularly in the alveolitis phase of sarcoidosis. MooDLEY et al. [13] did not find a significant correlation between eNO concentration and CD4:CD8 ratio on BAL. They suggested that iNOS induction in sarcoidosis is a response to the inflammatory processes of sarcoidosis in the airways and may not reflect the

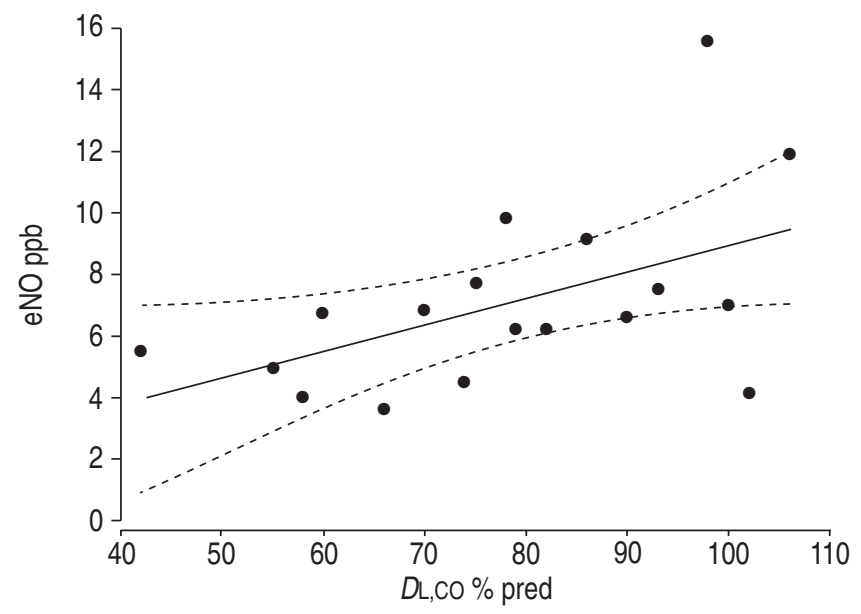

Fig. 8.-Relationship between exhaled nitric oxide (eNO) concentration and carbon monoxide diffusing capacity of the lung (DL,CO) in patients with sarcoidosis ( - : regression line; - - - -: 95\% confidence interval). ppb: parts per billion; $\%$ pred: percentage of the predicted value. $\mathrm{r}=0.515, \mathrm{p}=0.029$. granulomatous burden nor the structural changes taking place in the lung. The same authors demonstrated that eNO concentration did not correlate with numbers of any cell subset in BAL fluid in patients with or without interstitial lung disease in progressive systemic sclerosis. This suggests that eNO concentration reflects a different aspect of inflammation as opposed to the cellularity of BAL [23].

In the first study concerning eNO in sarcoidosis, $\mathrm{O}^{\prime}$ DONELL et al. [14] reported no significant differences in BAL fluid nitrite concentrations between patients and controls. All of these results would imply that there are several mechanisms accounting for the elevated level of eNO in patients with pulmonary sarcoidosis, rather than simply iNOS upregulation.

Although the present findings indicate that eNO concentration is elevated in patients with sarcoidosis, the eNO concentration was similar in patients at differing radiographic stages of the disease. The eNO concentration in patients with parenchymal infiltration (stages II and III) did not differ from that in patients with hilar lymphadenopathy alone (stage I). The second and third stages of sarcoidosis are characterised by chronic parenchymal inflammatory processes, in which an increased number of cells, especially type-1 T-helper cell-type T-lymphocytes and macrophages, is involved [11]. These cells release cytokines, which can promote expression of iNOS and increase the level of eNO. O'Donell et al. [14] showed no significant difference in eNO concentration between patients with hilar adenopathy alone and those with interstitial shadowing. The study group, however, was limited [14]. Moodley and Lalloo [23] demonstrated, in a study of patients with progressive systemic sclerosis, that eNO concentration was higher in those without than with interstitial infiltration.

No significant correlation was found between eNO concentration and FVC or forced expiratory volume in one second (FEV1) in the present patients, in agreement with the study of MoODLEY et al. [13]. It is possible that this lack of correlation is due to the small range of FVC and FEV1 in most patients. The present authors speculate that there must be other determinants of eNO concentration in patients with sarcoidosis.

Both alveolar and airway compartment-derived NO react with several substrates, including oxygen, superoxide, thiols and metalloproteins [24].

NO itself is short-lived in vivo (half-life $0.1-5 \mathrm{~s}$ [25]) and its rapid reaction with superoxide results in its inactivation. NO reacts with superoxide to produce peroxynitrite, which reacts predominantly with either glutathione or carbon dioxide. This is the major route for elimination of peroxynitrite [26]. JONES et al. [27] demonstrated that the superoxide generated by neutrophils causes a decrease in eNO concentration in patients with cystic fibrosis. It has been revealed that the consumption by superoxide of NO decreases from the large to the small airways. In small airways, the diffusion of NO is rapid and there is insufficient time for chemical reaction with superoxide [26]. The present authors speculate that this is potential mechanism for the modulation of eNO concentration in sarcoidosis.

The formation of $S$-nitrosothiols serves to stabilise NO in a form that is noncytotoxic [28]. S-nitrosothiols are biologically active as vasodilators and bronchodilators. Glutathione is the predominant endogenous thiol in human lung [29]. $S$ nitrosoglutathione demonstrates NO-like bioactivity and has been proposed as a possible carrier molecule for NO [26]. Inflammation and/or immune activation may be important stimulants of $S$-nitrosothiol generation [29]. GASTON et al. [30] demonstrated that tracheal $S$-nitrosothiol concentration is significantly lower in asthmatic children compared to controls, whereas expired airway NO concentration is higher. 
The authors proposed that $S$-nitrosothiol breakdown is accelerated in asthma, which leads to increased eNO levels. These findings in patients with asthma are not in line with the report of SHIN and GEORGE [26]. They proposed that only a fraction of intracellular NO consumption leads to $S$-nitrosoglutathione formation, the exhaled NO level is due to the diffusion of free NO from epithelial cells and $S$-nitrosoglutathione catabolism has minimal effect on NO concentrations in normal subjects.

Hunt et al. [31] suggested that $\mathrm{pH}$ is the determinant of $\mathrm{NO}$ concentration and bioactivities in the airways of subjects with acute asthma. Nitrite may serve as an NO reservoir, being converted to NO by airway acidification [31]. When the airway $\mathrm{pH}$ is acidic, there is evolution of NO from nitrite. Such a mechanism may potentially increase eNO concentrations [28]. Airway $\mathrm{pH}$ may be an important determinant of eNO concentration [31].

Notably, the present study showed that eNO concentrations are slightly higher in subjects with sarcoidosis than in controls and that the rise in eNO concentration in subjects with sarcoidosis is relatively smaller than that reported for patients with asthma [1] or pulmonary tuberculosis [20, 21]. SHIN and GEORGE [26] conclude that the majority of free NO in the mucus is due to the diffusion of free NO from epithelial cells and that these are the major source of eNO. MoODLEY et al. [13] suggested that the subepithelial location of granulomas in patients with sarcoidosis might result in impaired diffusion of $\mathrm{NO}$ into the airways in contrast to what is observed in asthma. Since NO diffuses over to the exhaled gas, the airway wall constitutes not only a producer of NO but also a barrier to its diffusion [32]. The transport of NO from its site of production to the bronchial blood or airstream occurs by molecular diffusion, as described by Fick's law [24].

It is possible that the above mechanisms for the production, consumption and transport of NO within the lungs determine eNO concentration and have created difficulty in interpreting the present results.

A weak correlation was found between eNO concentration and $D \mathrm{~L}, \mathrm{CO}$ in the present patients in opposition to the results of O'Donell et al. [14]. NO diffuses in and out of cell membranes thousands of times a second [25]. The exchange dynamics of NO in the lungs are different to those of endogenous gases such as oxygen and carbon dioxide because of specific differences in physical and biochemical properties. NO is derived from alveolar and airway sources, but these are two distinct regions with many different features, which may determine eNO concentration [24].

NO generated in the alveolar region may be derived from epithelium, endothelium or inflammatory cells, such as alveolar macrophages [8]. The NO concentration in exhaled breath depends on the exchange of NO in the alveolar compartment [24]. Transfer of gas may be limited by diffusion through the alveolar epithelium, interstitium, endothelium and plasma to the erythrocyte. The $D \mathrm{~L}, \mathrm{CO}$ reflects the rate of both diffusion and combination with haemoglobin [33]. DL,CO is measured commonly, but BORLAND and HigenBOTTAM [33] demonstrated that the diffusing capacity of the lung for $\mathrm{NO}(D \mathrm{~L}, \mathrm{NO})$ is four-fold greater than the $D \mathrm{~L}, \mathrm{CO}$. This difference is caused not only by $\mathrm{CO}$ or NO diffusion through the barrier but also by more rapid binding kinetics of NO to haemoglobin. It can, therefore, be predicted that NO uptake is diffusion-limited to a greater extent than that of $\mathrm{CO}[24,33]$. The rapid kinetics create a greater dependence of $D \mathrm{~L}$,NO on surface area available for diffusion [24]. These data would imply that eNO concentration increases with increasing $D \mathrm{~L}, \mathrm{CO}$ in the present patients. It is, therefore, possible that the positive correlation between eNO concentration and $D \mathrm{~L}, \mathrm{CO}$ in patients with sarcoidosis is one of the important factors determining eNO concentration. This finding is consistent with the small difference in eNO concentration between patients with sarcoidosis and healthy controls.

The present authors speculate that, when $D \mathrm{~L}, \mathrm{CO}$ is low, the diffusion of NO to the airway might be limited. The pathological processes within the lung of patients with sarcoidosis probably make the diffusion barrier thicker. Furthermore, the granulomas are located close to or within the connective tissue sheath of bronchioles and subpleural or perilobular spaces. Vascular involvement is also observed and pulmonary infiltrations may leave behind fibrotic changes [11]. This would imply that lower eNO concentrations may be determined by the thicker diffusion barrier rather than inflammation.

For both alveolar and airway region-derived NO, the bronchial and pulmonary circulation are considered to be an infinite sink [24].

A recent study by PAWLOSKI et al. [34] indicates that haemoglobin captures and preserves NO and forms $S$ nitrosothiol from imported NO. Moreover, in red blood cells, there is a mechanism for the transfer of the NO group from $S$-nitrosothiol-haemoglobin to the erythrocyte membrane. Increased export by erythrocytes of NO-related bioactivity may decrease the scavenging of endothelially derived NO [34]. The pulmonary arteries are in close anatomical proximity to membranous airways, and so it is likely that some pulmonary endothelial NO enters the airspace, thus permitting its measurement in exhaled breath [35]. The processes described above could also determine eNO concentration.

To the best of the present authors' knowledge, two other studies have investigated eNO concentration in patients with sarcoidosis. The results were somewhat conflicting. The present findings parallel those of MoODLEY et al. [13], who concluded that eNO concentration was raised in patients with active pulmonary sarcoidosis. On the contrary, $\mathrm{O}^{\prime}$ DONELL et al. [14] found no difference in eNO concentration when comparing subjects with active sarcoidosis to the control group.

The other studies concerning eNO concentration in patients with sarcoidosis employed the Logan R2000 nitric oxide analyser (Logan Research, Rochester, UK). This is a chemiluminescent analyser that is designed for on-line recording of exhaled NO concentration. The present study used the Sievers 280 nitric oxide analyser. The present methodology for eNO measurement, including the on-line method, is recommended by the ERS. Both methods are similar, allowing for valid comparisons between the results.

The two recent studies investigated a small number of patients, i.e. 12 and 10 , respectively $[13,14]$. The present study group consisted of 27 Caucasians, and is the largest group studied to date, with a predominance of males, although most studies suggest a slightly higher disease rate for females [11]. O'Donnell et al. [14] also studied Caucasians. MoodLeY et al. [13] suggested two reasons for the normal eNO concentration in their study group: absence of iNOS induction in the alveolar inflammation in sarcoidosis or inability to detect the excess NO production in the exhaled air. JONES et al. [27] demonstrated that an absence of an increase in eNO concentration does not exclude the possibility of NO participating in the inflammatory processes.

The patients studied by MoODLEY et al. [13] were mainly Africans with active progressive sarcoidosis with extrapulmonary involvement (e.g. eye and skin) and lung function impairment. African-American patients appear to have a higher rate of extrapulmonary involvement and chronic progressive disease [11]. The eNO concentration observed in the study of MoODLEY et al. [13] might have been influenced 
by the ethnic origin of their patients. The present patients showed only pulmonary sarcoidosis with minimal respiratory function impairment.

It is concluded that the eNO concentration in patients with sarcoidosis is elevated but that there is no correlation with the activity of the disease. The present findings indicate that eNO is not a simple marker of inflammation in sarcoidosis. eNO measurement does not reflect iNOS activity alone, since there are many determinants of the production, consumption and transport of $\mathrm{NO}$ in the lung. The present study also proves that $D \mathrm{~L}, \mathrm{CO}$ is an important factor for eNO concentration in patients with sarcoidosis.

Further research is needed to clarify the role of nitric oxide synthase immunoreactivity in the cells of bronchoalveolar lavage fluid in patients with sarcoidosis.

\section{References}

1. Kharitonov SA, Yates DH, Robbins RA, Logan-Sinclair R, Shinebourne EA, Barnes PJ. Increased nitric oxide in exhaled air of asthmatic patients. Lancet 1994; 343: 133-135.

2. Kharitonov S, Welle AU, O'Connor BJ, et al. Elevated levels of exhaled nitric oxide in bronchiectasis. Am J Respir Crit Care Med 1995; 151: 1889-1893.

3. Moncada S, Palmer R, Higgs E. Nitric oxide: physiology, pathophysiology and pharmacology. Pharmacol Rev 1991; 43: 103-142.

4. Quinn AC, Petros J, Vallance P. Nitric oxide: an endogenous gas. Br J Anaesth 1995; 74: 443-451.

5. Yates DH, Kharitonov SA, Thomas PS, Barnes PJ. Endogenous nitric oxide is decreased in asthmatic patients by inhibitor of inducible nitric oxide synthase. Am J Respir Crit Care Med 1996; 154: 247-250.

6. Kharitonov SA, Barnes PJ. Exhaled markers of pulmonary disease. Am J Respir Crit Care Med 2001; 163: 1693-1722.

7. Donelly LE, Barnes PJ. Expression and regulation of inducible nitric oxide synthase from human primary airway epithelial cells. Am J Respir Cell Mol Biol 2002; 26: 144-151.

8. Gillissen A, Loseke S, Hippeli S, Jewase M. Inducible nitric oxide synthase and its product in human lung. Curr Pneumonol 1997; 1: 7-20.

9. Miyakawa H, Sato K, Shinbori T, et al. Effects of inducible nitric oxide synthase and xanthine oxidase inhibitors on SEB-induced interstitial pneumonia in mice. Eur Respir $J$ 2002; 19: 447-457.

10. Pechkovsky DV, Zissel G, Stamme C, et al. Human alveolar epithelial cells induce nitric oxide synthase-2 expression in alveolar macrophages. Eur Respir J 2002; 19: 672-683.

11. Hunninghake GW, Costabel U, Masayuki A, et al. Statement on sarcoidosis. Joint Statement of the American Thoracic Society (ATS), the European Respiratory Society (ERS) and the World Association of Sarcoidosis and Other Granulomatous Disorders (WASOG), adopted by the ATS Board of Directors and by the ERS Executive Committee, February 1999. Am J Respir Crit Care Med 1999; 160: 736755.

12. Bilyk C, Holt PG. Cytokine modulation of the immunosuppressive phenotype of pulmonary alveolar macrophage population. Immunology 1995; 86: 231-237.

13. Moodley YP, Chetty R, Lalloo UG. Nitric oxide in exhaled air and inducible nitric oxide synthase immunolocalisation in pulmonary sarcoidosis. Eur Respir J 1999; 14: 822-827.

14. O'Donell DM, Moynihan J, Finlay GA, et al. Exhaled nitric oxide and bronchoalveolar lavage nitrite/nitrate in active pulmonary sarcoidosis. Am J Respir Crit Care Med 1997; 156: $11892-11896$.
15. Quanjer PH, ed. Standarized lung function testing. Report Working Party "Standardization of lung function tests" European Community for Coal and Steel. Bull Eur Physiopathol Respir 1983; 19: Suppl. 5, 8-95.

16. Klech H, Pohl W. Technical recommendations and guidelines for bronchoalveolar lavage (BAL). Report of the European Society of Pneumonology Task Group. Eur Respir J 1989; 2: 561-585.

17. Ziora D, Grzanka P, Mazur B, et al. Evaluation of alveolitis by bronchoalveolar lavage and high-resolution computed tomography in patients with sarcoidosis. $J$ Bronchol 2001; 7: 260-266.

18. Musialik J, Petelenz M, Jastrzebski D, et al. Lymphocyte subsets in peripheral blood and bronchoalveolar lavage in patients with primary biliary cirrhosis. Med Sci Monit 2001; 7: Suppl.1, 311-315.

19. Kharitonov S, Alving K, Barnes PJ. Exhaled and nasal nitric oxide measurement: recommendations. Eur Respir J 1997; 10: $1683-1693$.

20. Kuo HP, Wang $\mathrm{CH}$, Huang $\mathrm{KS}$, et al. Nitric oxide modulates IL- $1 \beta$ and TNF- $\alpha$ synthesis by alveolar macrophages in pulmonary tuberculosis. Am J Respir Crit Care Med 2000; 161: 192-199.

21. Wang CH, Liu CY, Lin HC, Yu CT, Chung KF, Kuo HP Increased exhaled nitric oxide in active pulmonary tuberculosis due to inducible NO synthase upregulation in alveolar macrophages. Eur Respir J 1998; 11: 809-815.

22. Spiteri MA, Clarke SW, Poulter LW. Alveolar macrophages that suppress T-cell responses may be crucial to the pathogenetic outcome of pulmonary sarcoidosis. Eur Respir $J$ 1992; 5: 394- 403 .

23. Moodley YP, Lalloo UG. Exhaled nitric oxide is elevated in patients with progressive systemic sclerosis without interstitial lung disease. Chest 2001; 119: 1448-1454.

24. Tsoukias NM, George SC. A two-compartment model of pulmonary nitric oxide exchange dynamics. J Appl Physiol 1998; 85: 653-666.

25. Beckman JS, Koppenol WH. Nitric oxide, superoxide, and peroxynitrite: the good, the bad and the ugly. Am J Physiol 1996; 271: C1434-C1437.

26. Shin HW, George SC. Microscopic modeling of NO and $S$ nitrosoglutathione kinetics and transport in human airways. J Appl Physiol 2001; 90: 777-788.

27. Jones KL, Bryan TW, Jinkins PA, et al. Superoxide released from neutrophils causes a reduction in nitric oxide gas. $\mathrm{Am}$ J Physiol 1998; 275: L1120-L1126.

28. Gaston B, Drazen JM, Loscalzo J, Stamler JS. The biology of nitrogen oxides in the airways. Am J Respir Crit Care Med 1994; 149: 538-551.

29. Gaston B, Reilly J, Drazen JM, et al. Endogenous nitrogen oxides and bronchodilator $S$-nitrosothiol in human airways. Proc Natl Acad Sci U S A 1993; 90: 10957-10961.

30. Gaston B, Sears S, Woods J, et al. Bronchodilator $S$ nitrosothiol deficiency in asthmatic respiratory failure. Lancet 1998; 351: 1317-1319.

31. Hunt JF, Fang K, Malik R, et al. Endogenous airway acidification. Implication for asthma pathophysiology. $A m$ J Respir Crit Care Med 2000; 161: 694-699.

32. Hogman M, Holmkvist T, Wegener T, et al. Extended NO analysis applied to patients with COPD, allergic asthma and allergic rhinitis. Respir Med 2002; 96: 24-30.

33. Borland CDR, Higenbottam TW. A simultaneous single breath measurement of pulmonary diffusing capacity with nitric oxide and carbon monoxide. Eur Respir J 1989; 2: 5663.

34. Pawloski JR, Hess DT, Stamler JS. Export by red blood cells of nitric oxide bioactivity. Nature 2001; 409: 622-626.

35. Borland C, Cox Y, Higenbottam T. Measurement of exhaled nitric oxide in man. Thorax 1993; 48: 1160-1162. 